\title{
Size and burden of social phobia in Europe
}

\author{
Lydia Fehm $^{\mathrm{a},{ }^{*}}$, Antoine Pelissolo ${ }^{\mathrm{b}}$, Tomas Furmark ${ }^{\mathrm{c}}$, Hans-Ulrich Wittchen ${ }^{\mathrm{d}, \mathrm{e}}$
}

\author{
a Department of Psychology, Humboldt-University Berlin, Rudower Chaussee 18, D-12489 Berlin, \\ Germany \\ ${ }^{\mathrm{b}}$ Department of Psychiatry and CNRS UMR 7593, Pitié-Salpétrière Hospital, Paris, France \\ ${ }^{c}$ Department of Psychology, Uppsala University, Uppsala, Sweden \\ ${ }^{\mathrm{d}}$ Department of Clinical Psychology and Psychotherapy, Technical University of Dresden, Dresden, \\ Germany \\ ${ }^{\mathrm{e}}$ Max-Planck-Institute of Psychiatry, Munich, Germany \\ *Corresponding author. Tel.: +49 302093 9309; fax: +49 302093 4859. E-mail address: \\ Lydia.Fehm@psychologie.hu-berlin.de (L.Fehm)
}

\begin{abstract}
This paper provides a critical review of the prevalence of social phobia in European countries, a description of associated disability and burden and of clinical correlates and risk factors associated with social phobia. On the basis of a comprehensive literature search we identified 21 community studies and two primary care studies. The median lifetime and 12-month prevalence rates of social phobia in community samples referring to DSM-III-R and DSM-IV criteria were $6.65 \%$ and $2.0 \%$, respectively. Younger individuals showed the highest rates, and women were more frequently affected than men. Social phobia was shown to be a persistent condition with a remarkably high degree of comorbid conditions, associated impairment and disability. Research deficits lie in a lack of data for most EU countries and in a lack of studies in children and the elderly. No data are available addressing met and unmet needs for intervention and costs, and data for vulnerability and risk factors of malignant course are scarce.
\end{abstract}

Keywords: Social phobia; Epidemiology; Prevalence; Europe

\section{Introduction}

In the past, social phobia and various other conditions were grouped together under the term of neurotic disorders in DSM-II or ICD-9. Only two and a half decades ago, in DSM-III (APA, 1980), it was recognized as a single diagnostic category (ICD-10: F 40.1; WHO, 1990). Since then, its significance as a highly impairing and persistent condition has been well documented. Also known as social anxiety disorder, social phobia is characterized by intensive fear reactions triggered by a wide variety of social situations, in which the person might be negatively evaluated by others. The anxiety is distinct and persistent, and it is often accompanied by disorder-specific bodily symptoms such as blushing, trembling, or sweating (Criterion A; DSM-IV; APA, 1994). When confronted with the feared situation, the individual immediately reacts with anxiety symptoms (Criterion B), whereas the person acknowledges that the fear is unreasonable and/or exaggerated (Criterion $\mathrm{C}$ ). The anxiety leads to avoidance of the feared situations or to intensive discomfort when avoidance is not possible (Criterion D). The experience of anxiety and its symptoms, the anticipatory anxiety, and avoidance behaviour typically lead to distinct impairment in role functioning and to associated 
disabilities (Criterion E). To delineate temporary developmental social phobic syndromes from clinically significant social phobia, for individuals under 18 years of age, the symptoms have to persist for at least 6 months (Criterion F). Social phobia symptomatology can also occur as a more or less transient syndrome due to substance use and withdrawal syndrome, and potentially embarrassing medical conditions (e.g. trembling in Parkinson's Disease, stuttering, or binge eating such as in eating disorders). Thus, to delineate social phobia from such substance and/or somatic condition-related syndromes, Criteria G and H from DSMIV require a series of differential diagnostic considerations. From the standpoint of epidemiological case finding methods, the latter differential diagnostic criteria as well as the impairment/distress criterion and the way they are translated in diagnostic interviews have been shown to be important sources of variation in prevalence estimates (Wittchen and Fehm, 2003). Also note that, since the introduction of social phobia in the DSM-III (APA, 1980), the diagnostic criteria have been subject to changes, in an attempt to provide a sharper description of the disorder (e.g. with regard to the range of trigger situations). Consequently, corresponding changes in diagnostic assessment instruments and tools have had some influence on resulting prevalence estimates. In particular, the definition or operationalisation of impairment (see Criterion E) has been shown to be among the most important sources for variations in prevalence findings (Pélissolo et al., 2000), as cases of social phobia may differ in the degree of severity. Design factors such as sampling process, sample size, and age group composition are other important sources of variability.

\section{Aims}

Our main objective in this paper was to review critically epidemiological studies on the prevalence and/or incidence of social phobia in European union (EU) countries, with the focus on studies using DSM-III-R or DSM-IV definitions. An additional objective was to highlight important clinical correlates of social phobia (including risk factors, sociodemographic characteristics and cost and burden indicators), as revealed by epidemiological research.

\section{Methods}

Focusing on epidemiological studies in the community or services conducted in European countries (plus Iceland, Norway and Switzerland), we performed a comprehensive search of literature databases (Web of Science, Medline). Studies published since 1980 and using DSMIII upwards diagnostic criteria were included. Search results were circulated among experts to supplement studies that were not identified and to include reports accepted for publication as well as unpublished data, if accessible. Results were also compared with search results of the European Brain Council (EBC) project group in Dresden (see Wittchen and Jacobi, 2005).

\section{Results}

\subsection{Prevalence studies}

As shown in Table 1, a considerable number of community studies is available $(n=21)$, the majority targeting the adult general population. Two studies have examined social phobia in primary care samples. Nearly all were cross-sectional prevalence studies; only two were longitudinal studies providing some information about incidence patterns (Wittchen et al., 
1999a, Merikangas et al., 2002). At first sight, these studies reveal a considerable degree of variation in terms of prevalence estimates. As noted above, a large part of this variation can be attributed to changes in the diagnostic criteria and to the instrument used in the respective study. Therefore, we discuss these findings according to the time when the study was conducted.

Early (pre-1990) studies based on DSM-III revealed- consistent with US American studiesfairly low lifetime prevalence estimates ranging between 1\% and 4\% (Degonda and Angst, 1993; Faravelli et al., 1989; Lindal and Stefansson, 1993, Wittchen et al., 1992). These initially low estimates were largely attributed to the fact that the diagnostic instruments used did not examine the condition in a separate diagnostic module, which possibly resulted in an underestimation of the true prevalence (Wittchen et al., 1999b).

Subsequent studies relying on the revised DSM-III-R criteria and expanded diagnosis-specific modules revealed considerably higher lifetime prevalence rates for social phobia ranging between 4.1\% (Lépine and Lellouch, 1995) and 16\% (Wacker et al., 1992). It is noteworthy that the authors of the Swiss study also reported a considerably lower ICD-10-based estimate of $9.5 \%$-despite using the same sample and instrument-without revealing where this divergence comes from. The probably most frequently cited international DSM-III-R prevalence estimate has been $13.3 \%$, as determined by the National Comorbidity Survey for the US adult population (Kessler et al., 1994; Magee et al., 1996).

Whereas the DSM-III criteria for social phobia were revised profoundly, only minor differences exist between the DSM-III-R and DSM-IV definitions. The DSM-IV assessment tools, however, were revised addressing more comprehensively social trigger situations as well as impairment issues. The lifetime prevalence in adult samples, when modern diagnostic criteria were used, ranged from 3.9\% in Belgium (Ansseau et al., 1999) to $13.7 \%$ in Norway (Kringlen et al., 2001); the median was 6.65\%. Twelvemonth prevalence ranged from $0.6 \%$ (Spain) to $7.9 \%$ (Norway), and the median was $2.0 \%$. Prevalence estimates were generally higher in women than in men. In few studies, shorter $(\leq 1$ month) prevalence periods have been reported, but these estimates varied between $1 \%$ and $15.6 \%$.

Table 1 also signals that only few EU countries, namely Belgium, France, Germany, Italy, the Netherlands, Spain and Sweden, have ever published any prevalence rates for community samples and a sizable age range. Further noteworthy issues are: (i) A small number of studies have been conducted using ICD-10 criteria for social phobia. (ii) In addition to community surveys, some surveys have also been conducted in general health care settings. In this domain, Szádóczky et al. (1997), who used the Diagnostic Interview Schedule (version III; DSM-III-R), reported a 4.9\% 12-month prevalence rate in Hungarian primary care settings. Weiller et al. (1996) reported a 4.9\% 1-month prevalence rate in a Paris sample of consecutive primary care attenders, using CIDI/DSM-III-R as part of the WHO Collaborative Study of Psychological Disorders in primary care. This French study showed no preponderance of women among individuals with social phobia in this clinical setting.

\subsection{Incidence, age of onset and course}

From an EU and international perspective, there is a lack of incidence studies. Only one EUbased study, the EDSP (Early Developmental Stages of Psychopathology; see Lieb et al., 2000a) provides incidence data for social phobia. This limits the degree to which firm conclusions can be drawn about age-related peak periods of risk of onset and to which estimates across the full lifespan can be derived. Social phobia is undoubtedly an early onset 
disorder in the majority of cases. Fairly stable across studies, the age of onset is reported in the range between 12 and 16.6 years (Wittchen et al., 1999a; Faravelli et al., 2000; Degonda and Angst, 1993; Schneier et al., 1992; Lépine and Lellouch, 1995; DeWit et al., 1999). When prevalence rates are differentiated by age group, they are generally found to decrease slightly across age groups (Bijl et al., 1998; Jacobi et al., 2004; Lépine and Lellouch, 1995). The onset of social phobia after the age of 25 seems to be rare (Wittchen et al., 1999a; see Fig. 1), but it might be premature to state that social phobia almost never occurs at higher ages for the first time.

Social phobia is generally regarded as a chronic condition. In epidemiological as well as in clinical studies, a duration of 10 and more years is frequently reported (Perugi et al., 1990; Davidson et al., 1993). Data from longitudinal studies point to a lower stability when only cases meeting all diagnostic criteria are considered (Müller, 2002; Degonda and Angst, 1993), but stability rates are rather high again when subthreshold cases are included (Merikangas et al., 2002; Müller, 2002). Thus, the course of social phobia seems to be characterized by oscillations around the diagnostic threshold. Incidence was found to be $2.8 \%$ over a 42 -month interval (Müller, 2002) in the prospective longitudinal EDSP study with a sample of 3021 adolescents and young adults (age 14-24). About half of the incident cases had a history of social fears at baseline.

\subsection{Gender differences and sociodemographic correlates}

Consistent with studies from other regions of the world, gender differences have been documented, with women being more frequently affected by social phobia than men (Davidson et al., 1993; Degonda and Angst, 1993; Faravelli et al., 2000; Lépine and Lellouch, 1995; Magee et al., 1996; Meyer et al., 2000; Schneier et al., 1992; Wittchen et al., 1999a, $2000 \mathrm{a}, \mathrm{b})$. Odds ratios range between 1.5 and 2.2. There is an ongoing discussion whether the gender difference in social phobia is less pronounced than in other anxiety disorders. In clinical samples, usually no gender differences or even slightly higher rates for men have been reported (Rapee et al., 1988; Solyom et al., 1986; Heimberg and Juster, 1995), and it is assumed that gender roles and social expectations play a significant role in explaining the heightened helpseeking behaviour found in male patients (e.g., Weinstock, 1999; Turk et al., 1998). Other sociodemographic correlates are poor financial situation, low social class, single or unmarried status, unemployment and poor education (Degonda and Angst, 1993; Wittchen et al., 1999a; Müller, 2002), but it remains unclear whether those factors are antecedents or consequences of social phobia.

\subsection{Comorbidity - associations with other mental disorders}

Comorbidity in social phobia seems to be the rule rather than the exception, and there is first evidence that comorbid disorders are not only purely temporal consequences, but that they are rather causally linked, as indicated by some type of dose-response relation between social phobia and subsequent depression (Stein et al., 2001).

Lifetime comorbidity has been reported to range between 69\% (Schneier et al., 1992) and $92 \%$ (Faravelli et al., 2000). In a representative sample of the German adult population (N =4181; Jacobi et al., 2002; Wittchen et al., 2000a) that covered a wide range of possible comorbid disorders, only $12 \%$ of all cases with the diagnosis of social phobia during the past 12 months were pure; all others had at least one other mental disorder (Fehm and Jacobi, unpublished data). Especially depressive disorders as well as other anxiety disorders and substance abuse have consistently been found to be associated with social phobia (Faravelli et 
al., 2000; Bisserbe et al., 1996; Degonda and Angst, 1993; Schneier et al., 1992; Lépine and Lellouch, 1995; Pini et al., 1997; Magee et al., 1996; Regier et al., 1998).

Inspections of the temporal patterns show that social phobia precedes the onset of major depression in the majority of cases (de Graaf et al., 2003; Kessler et al., 1996; Schatzberg et al., 1998; Weiller et al., 1996). Additionally, social phobia has been found not only to precede depression temporally, but also to be associated with a more malignant course of an already existing depression (shorter interval between two episodes, more depressive symptoms; Stein et al., 2001). A less pronounced temporal relation has been reported for other anxiety disorders, with specific phobias having their onset often before that of social phobia. Social phobia seems also to precede temporally alcohol abuse or dependence, but the relationship between social phobia and alcoholism is particularly complex (Lépine and Pélissolo, 1998).

The fact that the majority of persons affected by social phobia are also affected by other mental disorders has given rise to some conceptual discussions. Stimulated by considerable evidence from longitudinal studies, one question is whether social phobia as a frequent early onset primary disorder may be regarded as a risk factor for secondary complications, particularly the temporally secondary onset of depressive and substance use disorders (Sonntag et al., 2000; Stein et al., 2001).

It should also be noted that the high degree of comorbidity poses significant challenges in estimating what proportion of disability and impairment can be clearly attributed to social phobia and the comorbid presentations, respectively. Similar difficulties have become apparent in evaluating treatment rates (see below) as well as the specificity of vulnerability and risk factors.

\subsection{Risk factors}

Within the developmental model of social phobia, numerous risk factors have been identified, but to date, only a heuristic, but not empirically proven, etiological model can be formulated. Some of the factors could be confirmed in prospective, longitudinal designs that allow to establish unambiguously the sequence of the factors (see Kraemer et al., 1997).

Familial factors: The familial aggregation of social phobia has been shown in several studies (Reich and Yates, 1988; Fyer et al., 1993; Mannuzza et al., 1995; Stein et al., 1998); but in those studies, it remained unclear whether the familial clustering was specific for social phobia in relation to other anxiety disorders. More recent studies, covering a broader range of disorders assessed in parents as well as in offspring, pointed to a marked degree of specificity for the familial aggregation of social phobia (Lieb et al., 2000b; Merikangas et al., 2002).

Two sources of familial clustering have to be considered: (1) genetic vulnerability, which has been supported, e.g. by twin studies (Kendler et al., 1992, 1999); (2) factors in the family environment, such as parental modelling and the style of child-rearing.

In an experimental design, detrimental effects of mothers' anxious reactions towards animal stimuli, resulting in higher anxiety levels in the children could be demonstrated (Gerull and Rapee, 2002). Among different facets of rearing styles, especially the combination of rejection and overprotection has been found to be associated with a higher risk of social phobia (Lieb et al., 2000b; for an overview, see Hudson and Rapee, 2000). 
Temperamental factors: Among possible temperamental variables, especially a child's behavior characterized by withdrawal and inhibition in novel situations (behavioural inhibition) has been linked to the etiology of social phobia (Biederman et al., 2001; Fox and Henderson, 2000; Hayward et al., 1998; Schwartz et al., 1999; Turner et al., 1996). However, there are many methodological problems such as the retrospective design of some studies, the low stability of behavioural inhibition, and sample biases that hamper the interpretation of those studies (see Neal and Edelmann, 2003, for a critical review). In adults, social phobia with or without comorbid depression has been found to be significantly associated with very marked inhibited temperament, for instance with dramatically high harm avoidance traits and particularly low self-directedness levels (Pélissolo et al., 2002).

\subsection{Disability and quality of life}

Social phobia can be an extremely impairing condition, although most studies have failed so far to provide detailed results differentiated by gender, age groups and subtypes of the disorder. Available data on impairments come from different sources: clinical samples of selected individuals seeking for help; epidemiological samples either from the general population or from primary care settings; and case control studies. Case control studies compare individuals with social phobia with matched control groups, controlling for at least some possible confounding factors. As only a small portion of individuals with social phobia seek professional help, the generalisability of findings from clinical studies to the burden of social phobia in the community is limited. Many studies focused on differences among other clinical groups, mostly finding more similarities than differences between social phobia and other anxiety disorders or affective disorders with regard to associated disabilities and impairments (Kennedy et al., 2002; Lochner et al., 2003; Quilty et al., 2003).

Epidemiological studies have addressed various areas of functioning and well-being and yielded consistent results that point to a profoundly negative impact of social phobia on quality of life. Note that individuals with social phobia, even without comorbid disorders, exhibit a markedly lower quality of life, which is similar to that of depressed outpatients (Wittchen and Beloch, 1996). Social phobia is associated with negative outcomes not only in social functioning, family-life, and close relationships (Lampe et al., 2003; Patel et al., 2002; Stein and Kean, 2000; Wittchen et al., 1999a), but also in occupational and educational domains. For example, social phobia is associated with early leave of school (Stein and Kean, 2000), lower educational attainment (Katzelnick and Greist, 2001; Wittchen et al., 1999a), and a higher risk of being unemployed (Patel et al., 2002; Lampe et al., 2003). Moreover, individuals with social phobia are significantly more often engaged in jobs below their level of qualification (Bruch et al., 2003; Katzelnick and Greist, 2001). Some studies could demonstrate a linear association between the severity of the disorder (e.g. number of situations affected by social fears) and diverse indicators of impairment (Stein et al., 2000). In a recent clinical study, 771 patients with DSM-IV social phobia have been examined with the Various Impact of Social Anxiety disorder (VISA) scale and the clinical estimate of trained psychiatrists. The results showed that a professional, social, and medical burden can be specifically attributed to social phobia, independently of comorbid disorders (Pélissolo et al., 2004).

Disability days: The ESEMed study group (ESEMeD/MHEDEA 2000 Investigators, 2004b) interviewed 21,425 adult participants in six European countries (Belgium, France, Germany, Italy, the Netherlands, Spain). The index for work loss days for individuals with social phobia was $0.24(95 \% \mathrm{CI} 0.16-0.31)$, which is comparable to that of other anxiety and affective disorders (any anxiety disorder: $0.24,95 \% \mathrm{CI} 0.20-0.28$; any affective disorder: $0.24,95 \% \mathrm{CI}$ 
$0.20-0.28)$ and a lot higher than that of the comparison group with no disorder $(0.03,95 \% \mathrm{CI}$ $0.02-0.04$ ) and even higher than that of disturbing medical conditions (diabetes: $0.12,95 \% \mathrm{CI}$ $0.08-0.17$; heart disease: $0.18,95 \%$ CI $0.12-0.23$ ).

In the German National Health Survey (Jacobi et al., 2002), in which a representative sample of 4181 adults was interviewed with the CIDI, notably higher numbers of disability days during the past 12 months were found among individuals with social phobia $(\mathrm{M}=34.9$, $\mathrm{SD}=88.3)$ as compared to a group without mental disorders $(\mathrm{M}=9.9, \mathrm{SD}=30.1)$. The high number seems to be due to the comorbid condition of social phobia, which, in this study, comprised $88 \%$ of the social phobia group (pure social phobia: $\mathrm{M}=7.4, \mathrm{SD}=8.5$; comorbid: $\mathrm{M}=38.8, \mathrm{SD}=78.7$; Fehm and Jacobi, in preparation).

No data about early retirement attributable to social phobia and/or its consequences are available.

\subsection{Suicidality and premature death}

In American and European community studies, an increased risk of suicidality has been reported in patients with social phobia (Katzelnick et al., 2001; Lépine and Lellouch, 1995; Olfson et al., 2000; Schneier et al., 1992). In the French survey (Lépine and Lellouch, 1995), this increased incidence of suicidal ideation or suicide attempts was largely explained by the comorbidity with depression. But particularly in females, social phobia without depression was also associated with an elevated prevalence of suicidal tendencies (odds ratio for the rate of suicide attempts as compared with the controls: 6.1; 95\%CI 1.9-19.4). Wunderlich et al. (1998) have reported similar results, with social phobia being significantly associated with suicide attempts (OR 2.2, 95\%CI 2.3-8.3), but this association was not significant in a multivariate analysis including all major DSM-IV diagnoses.

Data about/on estimates of the risk of premature death associated with social phobia are not available.

\subsection{Help-seeking}

Individuals with social phobia are found to live with their disorder for years or even decades before contacting mental health services, and the portion of affected individuals seeking professional help is low. Especially non-comorbid cases are rarely in contact with the health care system (Patel et al., 2002; Schneier et al., 1992; Wittchen et al., 1999a). In contrast, the case control study by Wittchen et al. (2000b) revealed no difference between pure, comorbid and even subthreshold cases with regard to quality of life and psychiatric service use.

When individuals with social phobia are compared to other anxiety or affective disorders, they show comparably low rates of help-seeking behaviour (Bijl and Ravelli, 2000; Issakidis and Andrews, 2002; Issakidis et al., 2004; Patel et al., 2002; Schneier et al., 1992; Wittchen et al., 1999a). Several studies indicate that mental health services will not be called on until secondary problems such as depression or problematic substance use occur (Magee et al., 1996; Wittchen et al., 1999a).

Social phobia is still rarely detected by primary care physicians (Weiller et al., 1996) and even when the diagnosis is made correctly, the portion of cases receiving an empirically validated treatment is still low, as shown in Fig. 2 (data from Wittchen, 2000b). 
Apart from this data and studies conducted in American countries, little is known about the proportion of social phobia that is diagnosed and treated in either primary care or the specialty sector with drugs and/or psychological methods with established efficacy.

\subsection{Intervention}

To date, a range of psychological as well as pharmacological treatment approaches has been presented. The effectiveness of cognitive-behavioural interventions has been shown in numerous studies and already five metaanalytic reviews have been conducted (Fedoroff and Taylor, 2001; Feske and Chambless, 1995; Gould et al., 1997; Ruhmland and Margraf, 2001; Taylor, 1996). Effect sizes around 1.0 have been reported for integrated CBT and single components of it (e.g. only exposure, only cognitive restructuring). Even though the empirical evidence appears conclusive, it should be mentioned that all meta-analyses used different inclusion criteria and different effect size calculation procedures.

Among the pharmacological approaches, selective serotonin reuptake inhibitors (SSRIs) have been named as the first-line choice of treatment (Bandelow, 2002; Blanco et al., 2003; Davidson, 2003). Positive effects on the symptomatology have also been shown for other substances such as benzodiazepines, serotonin-norepinephrine reuptake inhibitors (SNRI) and monoamine oxidase inhibitors.

Although psychotherapy as well as pharmacological interventions have proven to be effective, there still are no conclusive empirical data with regard to the combination of both treatments. The additive effects of two effective treatments cannot be automatically assumed. It was recently reported that combining fluoxetine with cognitive-behavioural therapy did not yield further improvement compared with the monotherapies (Davidson et al., 2004).

The rather low response rate seems even more problematic. For example, according to Davidson (2003), only $35-65 \%$ of the patients receiving pharmacological treatment are regarded as responders.

Coming back to everyday life, social phobia is known to be associated with specific treatment barriers such as problems with clinical detection of the diagnoses, financial barriers, uncertainty over where to go for help, and fear of what others might think or say (Weiller et al., 1996; Olfson et al., 2000). In fact, although access to the health care system is more easily available to European than to US or Canadian citizens and is accessed to a higher degree, there is still a substantial proportion of individuals not being identified or not being sufficiently treated. Olfson et al. (2000) suggested that care access may be enhanced through raised public awareness of local services, the reduction of the psychological and financial burden of entering psychotherapy and increased health care professionals' awareness of the clinical and social significance of social phobia.

\subsection{Cost and burden indicators}

To date, no methodologically sound studies have provided estimates about the monetary costs of social phobia (Löthgren, 2004). However, high levels of unemployment, absenteeism from work, financial dependence on the state, use of prescribed medications, drug dependency, etc., in patients with social phobia suggest significant societal costs (Lécrubier et al., 2000; Patel et al., 2002). As an example, a community study in the US showed that $22.3 \%$ of the participants with pure generalized social phobia received financial disability or welfare benefits, as compared to $10.6 \%$ in controls (Schneier et al., 1992). 


\section{Discussion}

Our aim was to review the European prevalence of social phobia as defined by modern diagnostic criteria and to highlight epidemiological data of importance for the understanding of this disabling disorder. The main outcome was that, even though a total of 23 studies on prevalence were located, only a limited number of EU countries have actually examined this condition. This makes it difficult to draw firm conclusions about the EU-wide total prevalence and burden. However, the relative consistency of the available data does lead to the following statements:

Social phobia is a common disorder with a median lifetime prevalence of $6.65 \%$ and a high 12 -month prevalence of $2-3 \%$ when modern diagnostic criteria are applied. The difference between lifetime and 12-month risk might indicate a considerable variability in the natural course of this condition. The distribution of social phobia varied considerably across the countries surveyed, even when nations that are culturally and geographically close are compared. For instance, prevalence rates were lower in Finland than in its Scandinavian neighbours Norway and Sweden. However, due to design and instrument differences, it is premature to conclude that there is a substantial cultural or cross-national variation. Similar caution is also warranted with regard to the recent estimates of the pan- European ESEMeD study (ESEMeD/MHEDEA 2000 Investigators, 2004a), which appear to be lower than previous estimates. As noted by the principal investigator (WHO World Mental Health Survey Consortium, 2004), these preliminary (not peer reviewed) estimates should be treated with caution because there are obviously major design (sampling, stratification, missing items imputations leading to an underestimation) and technical complications that make interpretations difficult. Furthermore, these findings were based on diagnostic criteria and an instrument for which, at the time of the study, no reliability and validity were established and that used entirely new impairment and disability conventions (Wittchen and Jacobi, 2005).

Social phobia has its onset in adolescence, and it is highly persistent. Beside a marked reduction in diverse indicators of quality of life, everyday functioning is severely reduced not only in social, but also in educational and occupational domains. Social phobia is associated with higher risks of suicide and of developing other psychopathology. It has to be confirmed through future research whether the comorbid conditions are causal consequences or mere associations resulting from joint underlying factors. The first interpretation-if confirmedwould have considerable impact on early screening and early intervention of secondary complication as well as on prevention.

Another challenge lies in the improvement of access to the health care system both on the side of patients and on that of caregivers through optimising, for example, the detection rates of social phobia. As a first step, data on pathways of individuals with social phobia to mental health services are urgently needed to provide starting points for effective structural interventions. 
Talie 1

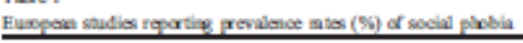

\begin{tabular}{|c|c|c|c|c|c|c|c|c|c|}
\hline Counsy & Saxe & $\mathrm{N}$ & hastument & $\begin{array}{l}\text { Agr } \\
\text { nalg }\end{array}$ & Lifetin $x$ & $\begin{array}{l}12 \\
\text { moats }\end{array}$ & $\begin{array}{l}12 \text { moats; } \\
\text { male }\end{array}$ & $\begin{array}{l}12 \text { mochs; } \\
\text { forme }\end{array}$ & s1 mad \\
\hline Belgu= & Anqein of all, 199 & 807 & $\mathrm{CDI}$ & $18-54$ & 3.9 & 20 & 1.3 & 27 & \\
\hline Fistaxt & Piscola \& al, 2005 & 6005 & Macmi & $30+$ & & 10 & 1.1 & as & \\
\hline Fance-4 & Lepine axt tellowet, 1996 & 1787 & modif. DISICDI & $18+$ & 4.1 & & & & \\
\hline Fanced & Pélibosolo \& al, 2000 & 12,873 & CIDI questionanire & $18+$ & 73 & & & & 23 \\
\hline Fance-Pyis" & Weiller et al, 1996 & 405 & $\mathrm{CDI}$ & & 14.4 & & & & 49 \\
\hline Frace-Monpelliar & Risclite ef al, 2004 & 1873 & MNI & $65+$ & 60 & & & & 12 \\
\hline Gomay-Muadelt & Wisthen \&al, $19 / 2$ & 483 & DIS & $25-64$ & 25 & & & & \\
\hline Gomany-Mudiel & Winchen \& a1, 1959 & 3021 & $\mathrm{CDI}$ & $14-24$ & 73 & 52 & 3.2 & 72 & \\
\hline Gemingy-abed & $\begin{array}{l}\text { Jacodi ef al, 2004; } \\
\text { Wiatien ef al, 2000a,b }\end{array}$ & 4181 & $\mathrm{CDI}$ & $18-65$ & & 20 & 1.3 & 27 & \\
\hline Hupery" & Srablesky \& al, $19 \pi$ & 301 & DIS questioanaire & $18-60$ & & 49 & 3.4 & 61 & \\
\hline loelant" & Lindal and Steflesseos, 1993 & 862 & DIS & $55-57$ & 3.5 & & & & \\
\hline Italy-Florenos" & Fanvelli i a al, 193 & 1110 & SADSA. & $15+$ & 1.0 & & & & \\
\hline Italy-Floerence & Fiemelli \& al, 2000 & 2355 & FPI & aot rep. & 40 & & & & \\
\hline Italy-Sesto Fiocentino & Fanvelli es al, 2004ab b & 2363 & FPI & $14+$ & 3.7 & 19 & 1.6 & 22 & 10 \\
\hline Nebletinds: & Bijl es al, 1998 & 7076 & $\mathrm{CDI}$ & $18-64$ & 7.8 & 48 & 3.5 & 61 & 37 \\
\hline Noewayac & & & & & & 2.3 & 1.4 & 33 & \\
\hline Noemaybs & Kinglen of al, 2001 & 2066 & $\mathrm{CDI}$ & $18-65$ & 13.7 & 79 & 45 & 11.1 & \\
\hline Polax & Rale-vibioaka of al, 2003 & 1929 & $\begin{array}{l}\text { CDI hows in } \\
\text { qustionacie }\end{array}$ & $14-20$ & 24.0 & & & & \\
\hline Spint & & 5473 & CDI quostionair & $18+$ & & a6 & 0.6 & 06 & \\
\hline Spin & Antho Croppo of al, 1998 & 237 & DIS querbionaire & $18-70$ & & & & 89 & \\
\hline Swoten & Furmatal, 199 & 1202 & posal suvey & $18-70$ & & & & & 156 \\
\hline Swiberland-Bwel & Waver a al, 1992 & 470 & $\mathrm{CDI}$ & $18-64$ & 160 & & & & \\
\hline 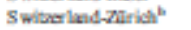 & Degooda and Aagh, 1973 & 3547 & SPIKE & $19-30$ & 3.8 & & & & \\
\hline S whorland-7intid & Merilayga \& al, 2002 & $591^{*}$ & SPIKF & $18-19$ & 6.0 & & & & \\
\hline
\end{tabular}

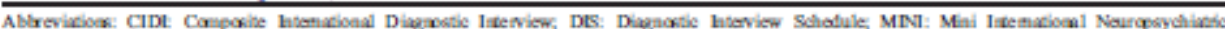

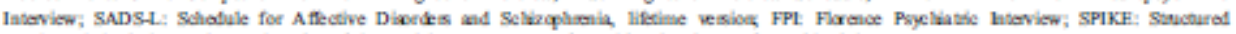

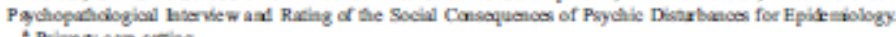

Primaly eare senting

DSM-III estitaria.

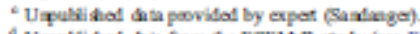

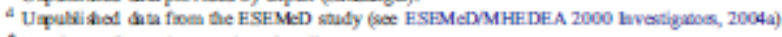

"Nusbes afer bo the sempie at buseline

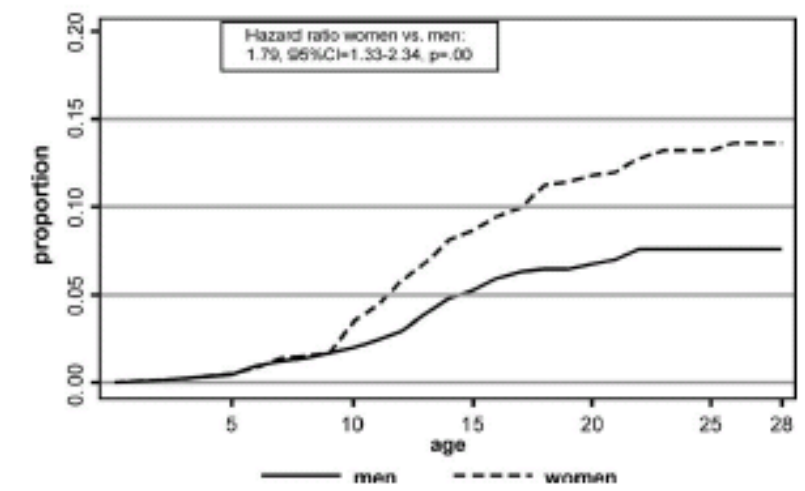

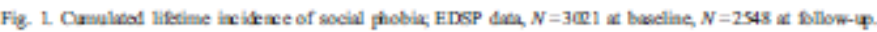

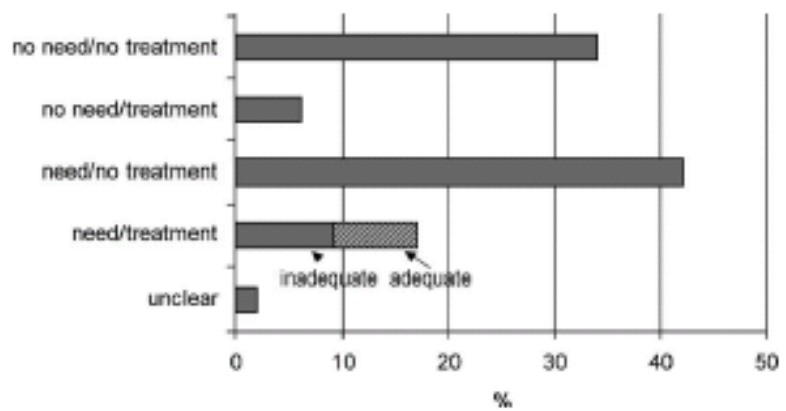

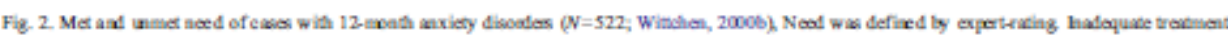

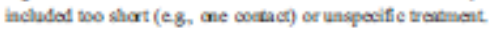




\section{References}

Ansseau, M., Reggers, J., Nickels, J., Magerus, S., 1999. Epidémiologie des troubles psychiatriques dans la province de Luxembourg, Plate-forme de concertation Psychiatrique. Université de Liège, Belgique.

APA, 1980. Diagnostic and Statistical Manual of Mental Disorders - DSM III. American Psychiatric Association, Washington, DC.

APA, 1994. Diagnostic and Statistical Manual of Mental Disorders, 4th edR American Psychiatric Association, Washington, DC.

Arillo Crespo, A., Aguinaga Ontoso, I., Guillen Grima, F., 1998. Prevalence of mental diseases in women of an urban area. Aten. Prim. 21, 265-269.

Bandelow, B., 2002. Medikamentöse Therapie der Sozialen Angststörung. In: Stangier, U., Fydrich, T. (Eds.), Soziale Phobie und Soziale Angststörung. Hogrefe, Göttingen, pp. 397-405.

Biederman, J., Hirshfeld-Becker, D.R., Rosenbaum, J.F., Hérot, C., Friedmann, D., Snidman, N., Kagan, J., Faraone, S.V., 2001. Further evidence of association between behavioral inhibition and social anxiety in children. Am. J. Psychiatry 158, 1673-1679.

Bijl, R.V., Ravelli, A., 2000. Psychiatric morbidity, service use, and need for care in the general population: results of the Netherlands Mental Health Survey and Incidence Study. Am. J. Public Health 90, 602-608.

Bijl, R.V., Ravelli, A., van Zessen, G., 1998. Prevalence of psychiatric disorder in the general population: results of the Netherlands Mental Health Survey and Incidence Study (NEMESIS). Soc. Psychiatry Psychiatr. Epidemiol. 33, 587-595.

Bisserbe, J.-C., Weiller, E., Boyer, P., Lépine, J.P., Lecrubier, Y., 1996. Social phobia in primary care: level of recognition and drug use. Int. Clin. Psychopharmacol. 11, 25-28.

Blanco, C., Schneier, F.R., Schmidt, A., Blanco-Jerez, C.R., Marshall, R.D., Sanchez-Lacay, A., Liebowitz, M.R., 2003. Pharmacological treatment of social anxiety disorder: a meta-analysis. Depress. Anxiety 18, 29-40.

Bruch, M.A., Fallon, M., Heimberg, R.G., 2003. Social phobia and difficulties in occupational adjustment. J. Couns. Psychol. 50, 109-117.

Davidson, J.R.T., 2003. Pharmacotherapy of social phobia. Acta Psychiatr. Scand. 108 (Suppl. 417), 65-71.

Davidson, J.R.T., Hughes, D.L., George, L.K., Blazer, D.G., 1993. The epidemiology of social phobia: findings from the Duke epidemiological catchment area study. Psychol. Med. 23, 709-718.

Davidson, J.R., Foa, E.B., Huppert, J.D., Keefe, F.J., Franklin, M.E., Compton, J.S., Zhao, N., Connor, K.M., Lynch, T.R., Gadde, K.M., 2004. Fluoxetine, comprehensive cognitive behavioral therapy, and placebo in generalized social phobia. Arch. Gen. Psychiatry 61 (10), 1005-1013.

Degonda, M., Angst, J., 1993. The Zurich Study XX. Social phobia and agoraphobia. Eur. Arch. Psychiatry Clin. Neurosci. 243, 95-102.

de Graaf, R., Bijl, R.V., Spijker, J., Beekmann, A.T.F., Vollebergh, W.A.M., 2003. Temporal sequencing of lifetime mood disorders in relation to comorbid anxiety and substance use disorders: findings from the Netherlands mental health survey and incidence study. Soc. Psychiatry Psychiatr. Epidemiol. 38, 1-11.

DeWit, D.J., Ogborne, A., Offord, D.R., MacDonald, K., 1999. Antecedents of the risk of recovery from DSM-III-R social phobia. Psychol. Med. 29, 569-582.

ESEMeD/MHEDEA 2000 Investigators, 2004a. Prevalence of mental disorders in Europe: results from the European Study of the Epidemiology of Mental Disorders (ESEMeD) project. Acta Psychiatr. Scand. 109 (Suppl. 1), 21-27.

ESEMeD/MHEDEA 2000 Investigators, 2004b. Disability and quality of life impact of mental disorders in Europe: results from the European Study of the Epidemiology of Mental Disorders (ESEMeD) project. Acta Psychiatr. Scand. 109 (Suppl. 1), 38-46.

Faravelli, C., Degl'Innocenti, B.G., Giardinelli, L., 1989. Epidemiology of anxiety disorders in Florence. Acta Psychiatr. Scand. 79, 308-312.

Faravelli, C., Zucchi, T., Viviani, B., Salmoria, R., Perone, A., Paionni, A., Scarpato, A., Vigliaturo, D., Rosi, S., D’Adamo, D., Bartolozzi, D., Cecchi, C., Abrardi, L., 2000. Epidemiology of social phobia: a clinical approach. Eur. Psychiatr. 15, 17-24. 
Faravelli, C., Abradi, L., Bartolozzi, D., Cecchi, C., Cosci, F., D’Adamo, D., Lo Iacono, B., Ravaldi, C., Scarpato, M.A., Truglia, E., Prodi, P.M., Rosi, S., 2004a. The Sesto Fiorentino Study: point and one year prevalences of psychiatric disorders in an Italian community sample using clinical interviewers. Psychother. Psychosom. 73, 226-234.

Faravelli, C., Abradi, L., Bartolozzi, D., Cecchi, C., Cosci, F., D’Adamo, D., Lo Iacono, B., Ravaldi, C., Scarpato, M.A., Truglia, E., Rosi, S., 2004b. The Sesto Fiorentino Study: background, methods and preliminary results. Psychother. Psychosom. 73, 216-225.

Fedoroff, I.C., Taylor, S., 2001. Psychological and pharmacological treatments of social phobia: a meta-analysis. J. Clin. Psychopharmacol. 21, 311 -324.

Feske, U., Chambless, D.L., 1995. Cognitive behavioral versus exposure only treatment for social phobia: a meta-analysis. Behav. Ther. 26, 695-720.

Fox, N.A., Henderson, H.A., 2000. Does infancy matter? Predicting social behavior from infant temperament. Infant Behav. Dev. 22, 445-455.

Furmark, T., Tillfors, M., Everz, P.-O., Marteinsdottir, I., Gefvert, O., Fredrikson, M., 1999. Social phobia in the general population: prevalence and sociodemographic profile. Soc. Psychiatry Psychiatr. Epidemiol. 34, 416-424.

Fyer, A.J., Mannuzza, S., Chapman, T.F., Liebowitz, M.R., Klein, D.F., 1993. A direct interview study of social phobia. Arch. Gen. Psychiatry 50, 286-293.

Gerull, F.C., Rapee, R.M., 2002. Mother knows best: effects of maternal modelling on the acquisition of fear and avoidance behaviour in toddlers. Behav. Res. Ther. 40, 2729-2787.

Gould, R.A., Buckminster, S., Pollack, M.H., Otto, M.W., Yap, L., 1997. Cognitive-behavioral and pharmacological treatment for social phobia: a meta-analysis. Clin. Psychol. Sci. Pract. 4, 291-306.

Hayward, C., Killen, J.D., Kraemer, H.C., Taylor, B., 1998. Linking selfreported childhood behavioral inhibition to adolescent social phobia. J. Am. Acad. Child Adolesc. Psych. 37, 1308-1316.

Heimberg, R.G., Juster, H.R., 1995. Cognitive-behavioral treatments: literature review. In: Heimberg, R.G., Liebowitz, M., Hope, D.A., Schneier, F.R. (Eds.), Social Phobia. Guilford Press, New York, pp. 261-309.

Hudson, J.L., Rapee, R.M., 2000. The origins of social phobia. Behav. Modif. 24, 102- 129.

Issakidis, C., Andrews, G., 2002. Service utilisation for anxiety in an Australian community sample.

Soc. Psychiatry Psychiatr. Epidemiol. 37, 153-163.

Issakidis, C., Sanderson, K., Corry, J., Andrews, G., Lapsley, H., 2004. Modelling the population costeffectiveness of current and evidencebased optimal treatment for anxiety disorders. Psychol. Med. 34, 19-35.

Jacobi, F., Wittchen, H.-U., Hölting, C., Sommer, S., Lieb, R., Höfler, M., Pfister, H., 2002.

Estimating the prevalence of mental and somatic disorders in the community: aims and methods of the German national health interview and examination survey. Int. J. Methods Psychiatr. Res. 11, 1-18.

Jacobi, F., Wittchen, H.-U., Hölting, C., Höfler, M., Pfister, H., Müller, N., Lieb, R., 2004. Prevalence, comorbidity and correlates of mental disorders in the general population: results from the German health interview and examination survey (GHS). Psychol. Med. 34, 593-611.

Katzelnick, D.J., Greist, J.H., 2001. Social anxiety disorder: an unrecognized problem in primary care. J. Clin. Psychiatry 62 (Suppl. 1), 11-16.

Katzelnick, D.J., Kobak, K.A., DeLeire, T., Henk, H.J., Greist, J.H., Davidson, J.R.T., Schneier, F.R., Stein, M.R., Helstad, C.P., 2001. Impact of generalized anxiety disorder in managed care. Am. J.

Psychiatry 158, 1999-2007.

Kendler, K.S., Neale, M.C., Kessler, R.C., Heath, A.C., Eaves, L.J., 1992. The genetic epidemiology of phobias in women: the interrelationship of agoraphobia, social phobia, situational phobia, and simple phobia. Arch. Gen. Psychiatry 49, 273-281.

Kendler, K.S., Karkowski, L.M., Prescott, C.A., 1999. Fears and phobias: reliability and heritability. Psychol. Med. 29, 539-553.

Kennedy, B.L., Lin, Y., Schwab, J.J., 2002. Work, social, and familiy disabilities of subjects with anxiety and depression. South. Med. J. 95, 1424-1427.

Kessler, R.C., McGonagle, K.A., Zhao, S., Nelson, C.B., Hughes, M., Eshleman, S., Wittchen, H.-U., 1994. Lifetime and 12-month prevalence of DSM-III-R psychiatric disorders in the United States. Arch. Gen. Psychiatry 51, 8-19. 
Kessler, R.C., Nelson, C.B., McGonagle, K.A., Swartz, M., Blazer, D.G., 1996. Comorbidity of DSMIII-R major depressive disorder in the general population: results from the US national comorbidity survey. Br. J. Psychiatry 168 (Suppl. 30), 17-30.

Kraemer, H.C., Kazdin, A.E., Offord, D.R., Kessler, R.C., Jensen, P.S., Kupfer, D.J., 1997. Coming to terms with the terms of risk. Arch. Gen. Psychiatry 54, 337-343.

Kringlen, E., Torgersen, S., Cramer, V., 2001. A Norwegian psychiatric epidemiological study. Am. J. Psychiatry 158, 1091-1098.

Lampe, L., Slade, T., Issakidis, C., Andrews, G., 2003. Social phobia in the Australian National Survey of Mental Health and Well-Being (NSMHWB). Psychol. Med. 33, 637-646.

Lécrubier, Y., Wittchen, H.-U., Faravelli, C., Bobes, J., Patel, A., Knapp, M., 2000. A European perspective on social anxiety disorder. Eur. Psychiatr. 15, 5-16.

Lépine, J.-P., Lellouch, J., 1995. Diagnosis and epidemiology of agoraphobia and social phobia. Clin. Neuropharmacol. 18 (Suppl. 2), 15-26.

Lépine, J.-P., Pélissolo, A., 1998. Social phobia and alcoholism: a complex relationship. J. Affect. Disord. 50, 23-28.

Lieb, R., Isensee, B., von Sydow, K., Wittchen, H.-U., 2000a. The Early Developmental Stages of Psychopathology Study (EDSP): a methodological update. Eur. Addict. Res. 6, 170-182.

Lieb, R., Wittchen, H.-U., Höfler, M., Fuetsch, M., Stein, M.B., Merikangas, K.R., 2000b. Parental psychopathology, parenting styles, and the risk of social phobia in offspring: a prospective longitudinal community study. Arch. Gen. Psychiatry 57, 859-866.

Lindal, E., Stefansson, J.G., 1993. The lifetime prevalence of anxiety disorders in Iceland as estimated by the US National Institute of Mental Health Diagnostic Interview Schedule. Acta Psychiatr. Scand. 88, 29-34.

Lochner, C., Mogotsi, M., du Toit, P.L., Kaminer, D., Niehaus, D.J., Stein, D.J., 2003. Quality of life in anxiety disorders: a comparison of obsessive-compulsive disorder, social anxiety disorder, and panic disorder. Psychopathology 36, 255-262.

Löthgren, M., 2004. Economic evidence in anxiety disorders: a review. Eur. J. Health Econ. 5, S20S25.

Magee, W.J., Eaton, W.W., Wittchen, H.U., McGonagle, K.A., Kessler, R.C., 1996. Agoraphobia, simple phobia, and social phobia in the National Comorbidity Survey. Arch. Gen. Psychiatry 53, 159168.

Mannuzza, S., Schneier, F.R., Chapman, T.F., Liebowitz, M., Klein, D.F., Fyer, A.J., 1995.

Generalized social phobia. Reliability and validity. Arch. Gen. Psychiatry 52, 230-237.

Merikangas, K.R., Avenevoli, S., Acharyya, S., Zhang, H., Angst, J., 2002. The spectrum of social phobia in the Zurich Cohort Study of young adults. Biol. Psychiatry 51, 81-91.

Meyer, C., Rumpf, H.-J., Hapke, U., Dilling, H., John, U., 2000. Lebenszeitprävalenz psychischer

Störungen in der erwachsenen Allgemeinbevölkerung: Ergebnisse der TACOS-Studie. Nervenarzt 71, 535-542.

Müller, N., 2002. Die soziale Angststörung bei Jugendlichen und jungen Erwachsenen:

Erscheinungsformen, Verlauf und Konsequenzen. Waxmann, Münster.

Neal, J.-A., Edelmann, R.J., 2003. The etiology of social phobia: toward a developmental profile. Clin. Psychol. Rev. 23, 761-786.

Olfson, M., Guardino, M., Struening, E., Schneier, F.R., Hellman, F., Klein, D.F., 2000. Barriers to the treatment of social anxiety. Am. J. Psychiatry 157, 521-527.

Patel, A., Knapp, M., Henderson, J., Baldwin, D., 2002. The economic consequences of social phobia. J. Affect. Disord. 68, 221-233.

Pélissolo, A., André, C., Moutard-Martin, F., Wittchen, H.-U., Lépine, J.P., 2000. Social phobia in the community: relationship between diagnostic threshold and prevalence. Eur. Psychiatr. 15, 25-28.

Pélissolo, A., André, C., Pujol, H., Yao, S.N., Servant, D., Braconnier, A., Orain-Pélissolo, S., Bouchez, S., Lépine, J.P., 2002. Personality dimensions in social phobics with or without depression. Acta Psychiatr. Scand. 105, 94-103.

Pélissolo, A., Santos, J., Richard-Berthe, C., 2004. Assessing the burden of social anxiety disorder: the VISA scale. Paper at the XXIV CINP Congress, Paris, June. Int. J. Neuropsychopharmacol., vol. 7, p. 371. 
Perugi, G., Simonini, E., Savino, M., Mengali, F., Cassano, G.B., Akiskal, H.S., 1990. Primary and secondary social phobia: psychopathologic and familial differentiations. Compr. Psychiatry 31, 245252.

Pini, S., Cassano, G.B., Simonini, E., Savino, M., Russo, A., Montgomery, S.A., 1997. Prevalence of anxiety disorders comorbidity in bipolar depression, unipolar depression and dysthymia. J. Affect. Disord. 42, 145-153.

Pirkola, S., Isometsä, E., Suvisaari, J., Aro, H., Joukamaa, M., Poikolainen, K., Koskinen, S., Aromaa, A., Lönnqvist, J., 2005. DSM-IV mood-, anxiety and alcohol use disorders and their comorbidity in the Finnish general population. Results from the Health 2000 study. Soc. Psychiatry Psychiatr. Epidemiol. 40, 1-10.

Quilty, L.C., Van Amerigen, M., Mancini, C., Oakman, J., Farvolden, P., 2003. Quality of life and the anxiety disorders. Anxiety Disord. 17, 405-426.

Rabe-Jablonska, J., Dietrich-Muszalska, A., Gmitrowicz, A., 2003. The prevalence of social phobia in a representative group of adolescents from Lodz. Psychiatr. Pol. 37, 87-95.

Rapee, R.M., Sanderson, W.C., Barlow, D.H., 1988. Social phobia features across the DSM-III-R anxiety disorders. J. Psychopathol. Behav. Assess. 10, 287-299.

Regier, D.A., Narrow, W.E., Kaelber, C.T., Schatzberg, A.F., 1998. Prevalence of anxiety disorders and their comorbidity with mood and addictive disorders. Br. J. Psychiatry 173 (Suppl. 34), 24-28.

Reich, J., Yates, W., 1988. Family history of psychiatric disorders in social phobia. Compr. Psychiatry 29, 72-75.

Ritchie, K., Artero, S., Beluche, I., Ancelin, M.-L., Mann, A., Dupuy, A.-M., Malafosse, A., Boulenger, J.-P., 2004. Prevalence of DSM-IV psychiatric disorder in the French elderly population. Br. J. Psychiatry 184, 147-152.

Ruhmland, M., Margraf, J., 2001. Effektivität psychologischer Therapien von generalisierter Angststörung und sozialer Phobie: Meta-Analysen auf Störungsebene. Verhaltenstherapie 11, 27-40. Schatzberg, A.F., Samson, J.A., Rothschild, A.J., Bond, T.C., Regier, D.A., 1998. McLean hospital depression research facillity: early-onset phobic disorders and adult-onset major depression. Br. J. Psychiatry 173(Suppl. 34), 29-34.

Schneier, F.R., Johnson, J., Hornig, C.D., Liebowitz, M.R., Weissman, M.M., 1992. Social phobia: comorbidity and morbidity in an epidemiologic sample. Arch. Gen. Psychiatry 49, 282-288.

Schwartz, C.E., Snidman, N., Kagan, J., 1999. Adolescent social anxiety as an outcome of inhibited temperament in childhood. J. Am. Acad. Child Adolesc. Psych. 38, 1008-1015.

Solyom, L., Ledwidge, B., Solyom, C., 1986. Delineating social phobia. Br. J. Psychiatry 149, 464 470 .

Sonntag, H., Wittchen, H.-U., Höfler, M., Kessler, R.C., Stein, M.B., 2000. Are social fears and DSMIV social anxiety disorder associated with smoking and nicotine dependence in adolescents and young adults? Eur. Psychiatr. 15, 67-74.

Stein, M.B., Kean, Y.M., 2000. Disability and quality of life in social phobia: epidemiologic findings. Am. J. Psychiatry 157,1606-1613.

Stein, M.B., Chartier, M.J., Hazen, A.L., Kozak, M.V., Tancer, M.E., Lander, S., Furer, P., Chubaty, D., Walker, J.R., 1998. A directinterviewing family study of generalized social phobia. Am. J.

Psychiatry $155,90-97$.

Stein, M.B., Torgrud, L.J., Walker, J.R., 2000. Social phobia symptoms, subtypes, and severity: findings from a community sample. Arch. Gen. Psychiatry 57, 1046-1052.

Stein, M.B., Fuetsch, M., Müller, N., Höfler, M., Lieb, R., Wittchen, H.-U., 2001. Social anxiety disorder and the risk of depression: a prospective community study of adolescents and young adults. Arch. Gen. Psychiatry 58, 251-256.

Szádóczky, E., R1'hmer, Z., Papp, Z., Füredi, J., 1997. The prevalence of affective and anxiety disorders in primary care practice in Hungary. J. Affect. Disord. 43, 239-244.

Taylor, S., 1996. Meta-analysis of cognitive-behavioral treatments for social phobia. J. Behav. Ther. Exp. Psychiatry 27, 1-9.

Turk, C.L., Heimberg, R.G., Orsillo, S.M., Holt, C.S., Gitow, A., Street, L.L., Schneier, F.R., Liebowitz, M.R., 1998. An investigation of gender differences in social phobia. J. Anxiety Disord. 12,209-223.

Turner, S.M., Beidel, D.C., Wolff, P.L., 1996. Is behavioral inhibition related to the anxiety disorders? Clin. Psychol. Rev. 16, 157-172. 
Wacker, H.-R., Müllejans, R., Klein, K.H., Battegay, R., 1992. Identification of cases of anxiety disorders and affective disorders in the community according to ICD-10 and DSM-III-R by using the Composite International Diagnostic Interview (CIDI). Int. J. Methods Psychiatr. Res. 2, 91-100. Weiller, E., Bisserbe, J.-C., Boyer, P., Lépine, J.P., Lecrubier, Y., 1996. Social phobia in general health care: an unrecognised undertreated disabling disorder. Br. J. Psychiatry 168, 169-174.

Weinstock, L.S., 1999. Gender differences in the presentation and management of social anxiety disorder. J. Clin. Psychiatry 60 (Suppl.9), 9-13.

WHO, 1990. The ICD-10 Classification of Mental and Behavioural Disorders. Clinical descriptions and Diagnostic Guidelines. World Health Organization, Division of Mental Health, Geneva. WHO World Mental Health Survey Consortium, 2004. Prevalence, severity and unmet need for treatment of mental disorders in the Word Health Organization World Mental Health Surveys. JAMA 291, 2581-2590.

Wittchen, H.-U., 2000. Met and unmet need for interventions in community cases with anxiety disorders. In: Andrews, G., Henderson, S. (Eds.), Unmet Need in Psychiatry: Problems, Resources, Responses. Cambridge University Press, Cambridge, pp. 256-276.

Wittchen, H.-U., Beloch, E., 1996. The impact of social phobia on quality of life. Int. Clin.

Psychopharmacol. 11, 15-23.

Wittchen, H.-U., Fehm, L., 2003. Epidemiology and natural course of social fears and social phobia. Acta Psychiatr. Scand. 108 (Suppl. 417), 4-18.

Wittchen, H.-U., Jacobi, F., 2005. Size and burden of mental disorders in Europe - a critical review and appraisal of 27 studies. Eur. Neuropsychopharmacol 15, 357-375.

Wittchen, H.-U., Essau, C.A., Zerssen, D.v., Krieg, C.J., Zaudig, M., 1992. Lifetime and six-month prevalence of mental disorders in the Munich follow-up study. Eur. Arch. Psychiatry Clin. Neurosci. 241, 247-258.

Wittchen, H.-U., Stein, M.B., Kessler, R.C., 1999a. Social fears and social phobia in a community sample of adolescents and young adults: prevalence, risk factors and co-morbidity. Psychol. Med. 29, 309-323.

Wittchen, H.U., Üstün, T.B., Kessler, R.C., 1999b. Diagnosing mental disorders in the community: a difference that matters? Psychol. Med. 29, 1021-1027.

Wittchen, H.-U., Pfister, H., Schmidtkunz, B., Winter, S., Müller, N., 2000a. German National Health Interview and Examination Survey - Mental Health Supplement (GHS-MHS): Part 2. Tables and instructions for public use file (supplement to final report BMBFBW 01 EH 9701/8). Munich: MaxPlanck-Institute for Psychiatry, Clinical Psychology and Epidemiology [The public use file can be ordered at: jacobi@psychologie.tu-dresden.de].

Wittchen, H.-U., Fuetsch, M., Sonntag, H., Müller, N., Liebowitz, M., 2000b. Disability and quality of life in pure and comorbid social phobia: findings from a controlled study. Eur. Psychiatr. 15, 46-58. Wunderlich, U., Bronisch, T., Wittchen, H.-U., 1998. Comorbidity patterns in adolescents and young adults with suicide attempts. Eur. Arch. Psychiatry Clin. Neurosci. 248, 87-95. 